\title{
My Favorite Animal, Amphioxus: Unparalleled for Studying Early Vertebrate Evolution
}

\author{
Hector Escriva
}

Amphioxus represents the most basally divergent group in chordates and probably the best extant proxy to the ancestor of all chordates including vertebrates. The amphioxus, or lancelets, are benthic filter feeding marine animals and their interest as a model in research is due to their phylogenetic position and their anatomical and genetic stasis throughout their evolutionary history. From the first works in the 19th century to the present day, enormous progress is made mainly favored by technical development at different levels, from spawning induction and husbandry techniques, through techniques for studies of gene function or of the role of different signalling pathways through embryonic development, to functional genomics techniques. Together, these advances foretell a plethora of interesting developments in the world of research with the amphioxus model. Here, the author review the discovery and development of amphioxus as a superb model organism in evolutionary and evolutionary-developmental biology.

\section{My First Contact with Amphioxus}

It was 1989 and I was studying my third year of biology at the University of Valencia in Spain. In the zoology course, we started the study of the chordate phylum, and in particular the cephalochordate group (i.e., the amphioxus), which was described by our teacher as our closest relative in evolutionary terms. This close evolutionary relationship with vertebrates was established since Gabriel Costa in $1834^{[1]}$ described the presence of a notochord in amphioxus. In addition, numerous studies later showed the substantial conservation at the anatomical level between amphioxus and vertebrates. Likewise, the urochordates (i.e., including the ascidians), which are the third group of chordates, are extremely divergent in anatomical terms (and today we know that that is also the case at the genomic level). ${ }^{[2]}$ As a result suggested by recent phylogenomic studies, we now know that these phylogenetic relationships are not correct, because the sister group of vertebrates are the urochordates and not the cephalocordates, which represent the most basally divergent clade in the phylum (Figure 1) ${ }^{[3-5]}$ At that point in our zoology course, a strike began, and it lasted the rest of the year. This prevented me from studying amphioxus because the

\section{Dr. H. Escriva}

Sorbonne Université

CNRS, Biologie Intégrative des Organismes Marins, BIOM

Banyuls-sur-Mer F-66650, France

E-mail: hescriva@obs-banyuls.fr chordate phylum was excluded from the final exam. However, I personally studied what the Brusca and Brusca ${ }^{[6]}$ text book said about amphioxus, which started to become "my favourite animal."

Years later, during my $\mathrm{PhD}$ at the Pasteur Institute in Lille, France, our paths crossed again. This second contact with amphioxus was only "molecular," because I was studying the evolution of the nuclear receptor (NR) gene family and I received an Eppendorf tube with some amphioxus genomic DNA to amplify NR fragments by PCR. Later, the results of this $\operatorname{work}^{[7]}$ motivated my postdoctoral research at the "Ecole Normale Superieure de Lyon" to study the function of some of these NRs during the embryonic development of amphioxus. That's how, in 1999, I got to go for the first time to Tampa, Florida, where I met colleagues from all the Western laboratories interested in amphioxus studies. Why in Tampa? Because it was the place where Nicholas and Linda Holland, the couple of researchers who can be considered the "parents" of modern amphioxus research, discovered how to obtain amphioxus embryos with a simple electric shock to mature adults. ${ }^{[8]}$ So, it was there, at the Courtney Campbell Causeway in Tampa, that we used to meet every summer to collect amphioxus adults, to induce their spawning and to obtain embryos. It was also there that I saw for the first time this peculiar animal with a dorsal notochord that, unlike vertebrates, persists in the adult, with an extremely simple dorsal neural tube but slightly thickened in the anterior part called the cerebral vesicle. I could also observe its $\mathrm{V}$-shaped myotomes, its ventral segmented gonads and gill slits, its hepatic caecum-the homologue of our liver- and its unique frontal eye-also homologue of our eyes (Figure 2). I was also fascinated by the beauty of the amphioxus embryos, which develop quite fast (from the egg to the larvae in about $72 \mathrm{~h}$ ) (Figure 3) and which are small and transparent, allowing classical experiments of developmental biology such as whole-mount in situ hybridization (ISH), or immunolocalization, to be easily performed.

\section{From Florida to Banyuls sur Mer}

There are about 30-35 amphioxus species described around the world, all of which are benthic filter feeding animals. ${ }^{[9]}$ They live in shallow waters (from just a few centimetres to about $50 \mathrm{~m}$ deep, although there are some much deeper examples, ${ }^{[10,11]}$ ). 


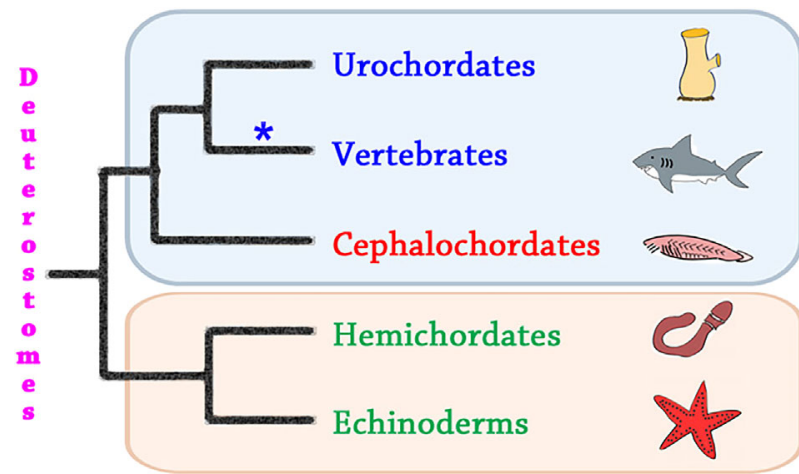

Figure 1. Schematic representation of the phylogenetic relationships between deuterostome phyla. The cephalochordates (i.e., amphioxus) are the earliest divergent lineage within chordates (blue box), which also comprise the urochordates (including ascidians) and their sister group, the vertebrates. The asterisk indicates the moment when at least two complete genome duplications occurred during evolution. The sister group of chordates, the Ambulacraria (brown box), include the echinoderms (i.e., sea urchins, starfish, etc.) and hemichordates (i.e., acorn worms).

They always live in sandy bottoms but the granulometry depends on the species and the site. Amphioxi are gonochoric animals and reproduce only during their spawning season, which varies slightly between species but which usually corresponds to spring and summer months. Although all amphioxus species spawn shortly after sunset, their spawning behavior also varies between species. Thus, while in the Florida species (Branchiostoma floridae) the animals spawn synchronously about once every 2 weeks, ${ }^{[12]}$ in the Mediterranean species (Branchiostoma lanceolatum) spawning occurs gradually during the spawning season, without any conspicuous synchronization. ${ }^{[13]}$

As I said before, Nicholas and Linda Holland had developed a method to induce spawning of adult amphioxus in the laboratory in Tampa. ${ }^{[8]}$ This method consists of a simple electric shock to individuals separated one by one in small plastic cups filled with sea water. But this method only works if it is applied on the day of natural spawning (I remember here that for the Florida species all animals from a given site spawn the same day in a synchronized way). Thus, a classic working day consists in collecting amphioxus on the beach every afternoon (simply with a shovel and a sieve) and after sunset, in the laboratory, one can try the electric shock. If it is not the natural spawning day, no embryos are obtained and everything starts again the next day. This method, although tedious and unpredictable (the natural spawning day cannot be predicted), allowed numerous laboratories to perform the first Evo Devo studies with amphioxus. However, for the European research teams, the work in Tampa represented an enormous investment of time and money since in a month's work and hopefully we could get embryos only 3 or 4 nights, which slowed down the development of the different technical approaches and research projects. For this reason, and given that the presence of amphioxus near the Banyuls sur Mer marine station in the south of France had been described, ${ }^{[14]}$ I organized in December 2001 a meeting in this marine station to which I invited all the European teams interested in amphioxus to try to develop the necessary techniques to work with the Mediterranean species, Branchiostoma lanceolatum. Most of the groups accepted the challenge and we started working with this species in Banyuls sur Mer.

\section{From the Electric Shock to the Thermal Shock}

In Banyuls sur Mer, unlike Tampa, collection of adult amphioxus with a shovel and a sieve was impossible because the animals live at $4-50 \mathrm{~m}$ depth. In the year 2002, we began our study trying to reproduce the way it was working in Tampa. For this, we used a boat from the marine station, which could collect amphioxus with a Charcot Picard dredge once a week, and we tried to induce the spawning with an electric shock every collection day at sunset. However, collecting animals once a week posed a problem. In 2002, we did not know the spawning behavior of B. lanceolatum, so if the Mediterranean amphioxus spawned synchronically like $B$. floridae and the natural spawning day was not the day of animal collection, we would never get spawning in the laboratory, and that is what happened. Therefore, the
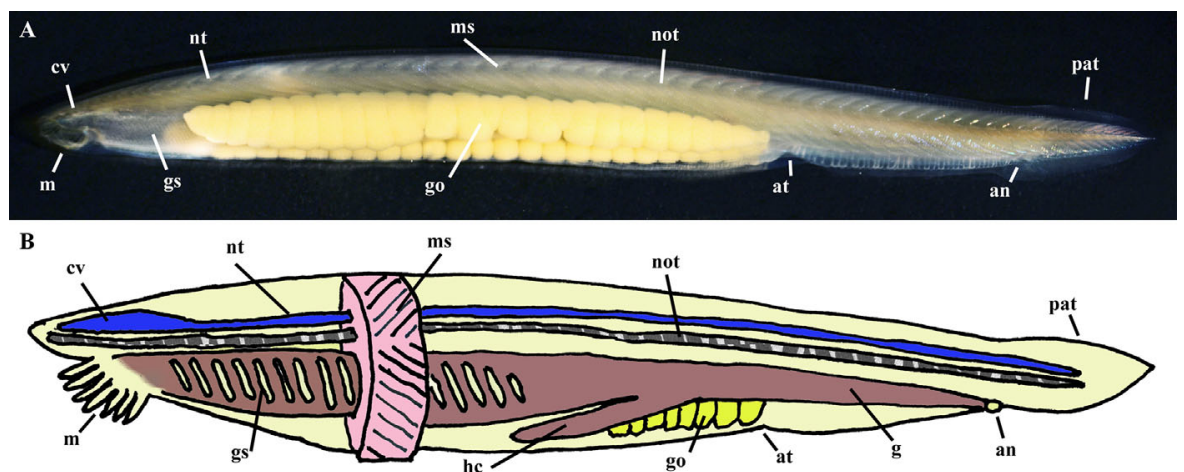

Figure 2. The amphioxus shares with vertebrates a large number of characteristics (chordate synapomorphies). A) Photograph of an adult amphioxus (Branchiostoma lanceolatum) from the Mediterranean (collected at the Racou beach, close to Banyuls sur Mer, France). The front part is on the left and the dorsal part is at the top. B) Schematic representation of an adult amphioxus. cv, cerebral vesicle; nt, hollow neural tube; ms, $V$ shape myotomes; not, notochord; pat, post-anal tail; m, mouth; gs, gill slits; go, gonads; at, atriopore; an, anus; hc, hepatic caecum; g, gut. 

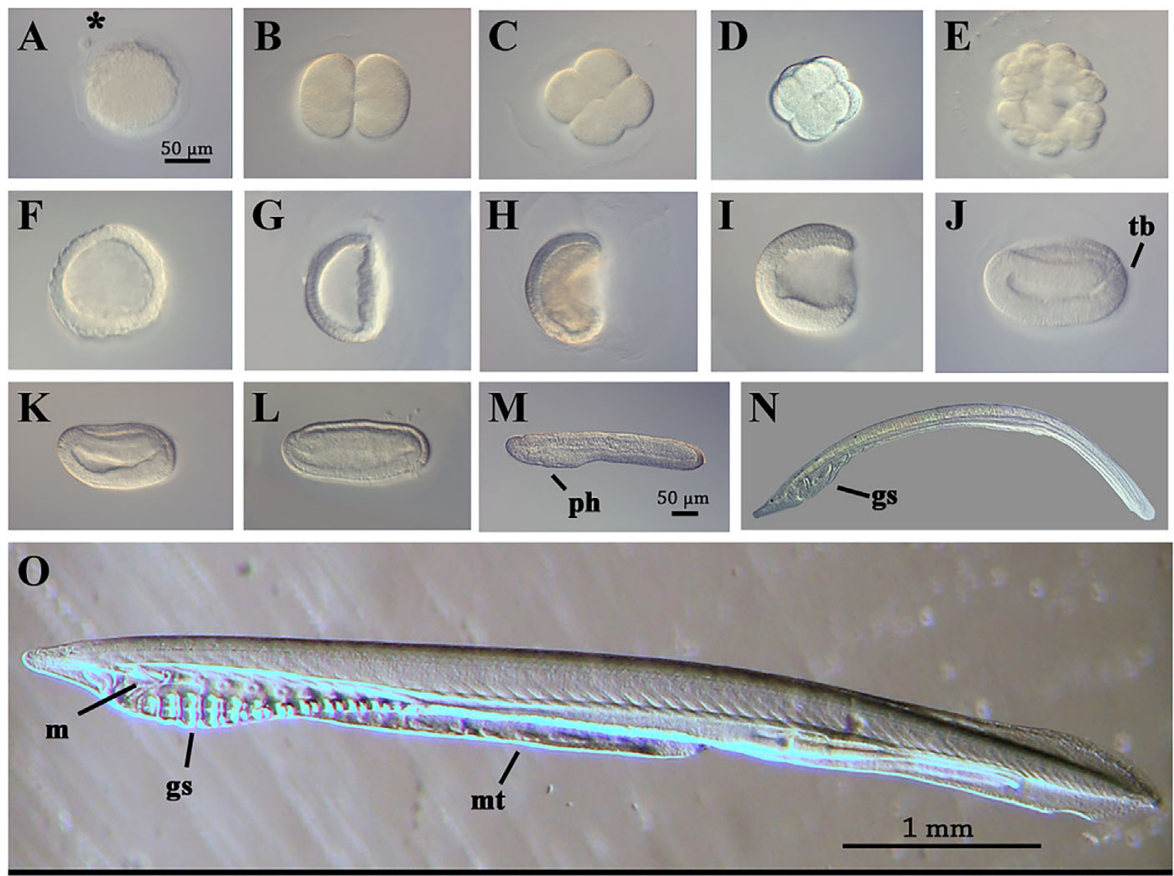

$\mathbf{P}$
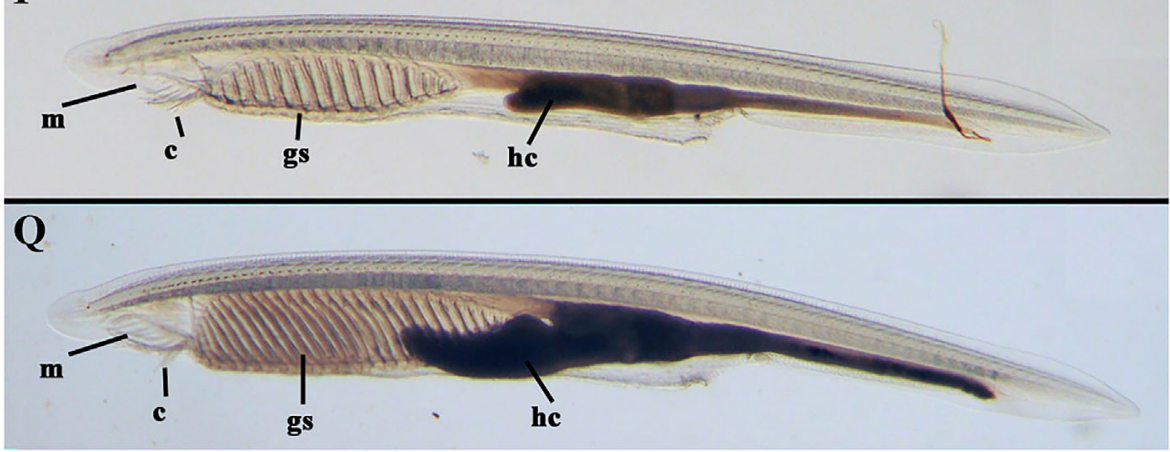

Figure 3. The amphioxus life cycle. The pictures show different developmental stages of the Mediterranean amphioxus. After spawning, the first polar body can be clearly observed next to the egg (see asterisk in A). The first division (B) occurs approximately 75 min post fertilization (at $19^{\circ} \mathrm{C}$ ). The following divisions at $19^{\circ} \mathrm{C}$ occur approximately every $45 \mathrm{~min}$ (C, four cells stage; $\mathrm{D}$, eight cells stage in which 4 micromeres and four macromers are observed). The morula stage or cleavage stage (E) is observed at $4 \mathrm{~h}$ post fertilization (hpf). The blastula (F) develops at $5 \mathrm{hpf}$, and quickly the vegetal pole invaginates during gastrulation to form the mesendoderm (G, early gastrula at $6 \mathrm{hpf;} H$, mid-gastrula at $8 \mathrm{hpf}$; I, late gastrula at $11 \mathrm{hpf}$ ). Neurulation begins with the closure of the blastopore at the posterior part of the embryo generating the tailbud (J, early neurula, $15 \mathrm{hpf}$; K, early-mid-neurula, 17-18 hpf; L, mid-neurula, $24 \mathrm{hpf}$; and M, late-neurula, also called pre-mouth stage, 36-40 hpf). In the late neurula, the pharynx swells where the mouth and first gill slit will develop (M). The larval stage begins when the mouth is opened, from 60 to $70 \mathrm{hpf}(\mathrm{N})$. The amphioxus larvae are left-right asymmetric. Some examples of this asymmetry are the mouth, which opens on the left side, and the gill slits that develop ventrolaterally on the right side. The somites also develop asymmetrically, with the left somites displaced half segment to the front compared to the right somites. The larvae continue to grow accumulating gill slits (depending on the amphioxus species this period varies quite a bit from a couple of weeks in $B$. floridae to $2-3$ months in $B$. lanceolatum). Thus, the larva that is presented in N, has developed three gill slits. At 2-3 months the larvae undergo a process of metamorphosis, the most important aspects of which are a considerable reduction in asymmetry (the mouth migrates and eventually positions medially, the gill slits duplicate and are placed in pairs on each side of the pharynx, but the muscle blocks derived from the somites are still asymmetrical). In $\mathrm{O}$ a larva that has begun the metamorphosis is shown. The development of the metapleural folds is observed in $\mathrm{O}$. In $\mathrm{P}$ the larva is in the middle of metamorphosis, the mouth is already located medially, the cirri begin to develop as well as the hepatic caecum. In Q the metamorphosis has culminated and the juvenile already has all the typical structures of the adult. Another interesting aspect of the metamorphosis process is the change in lifestyle from a pelagic life for the larva to a benthic life for the juvenile and adult. All the pictures from $\mathrm{G}$ to $\mathrm{Q}$ show the embryos with the anterior part to the left. tb, tailbud; ph, pharynx; gs, gill slits; mt, metapleural folds; m, mouth; c, cirri; hc, hepatic caecum. Scale bar in A represents $50 \mu m$ and applies from A to L. Scale bar representing $50 \mu \mathrm{m}$ in $\mathrm{M}$ applies also to $\mathrm{N}$. Scale bar in $\mathrm{O}$ represents $1 \mathrm{~mm}$ and applies from $\mathrm{O}$ to $\mathrm{Q}$. 
following year, in May 2003, we decided to rent a boat with which we were able to collect animals every day with a Van Veen dredge. Our first results showed two things, i) the electric shock, despite inducing spawning as in Tampa, activated the eggs, which prevented in vitro fertilization and ii) the spawning behavior of B. lanceolatum differed from that of the Florida species, since the animals did not spawn eggs synchronically.

Since the electric shock technique could not be used, we tried the way in which embryos were obtained at that time in the Asian species of amphioxus (B. belcheri). ${ }^{[15]}$ This technique, of simple observation of the adults in culture, involved waiting for the natural spawning in the tanks to recover the embryos from the water. Luckily, or by serendipity, while the month of June is warm in Banyuls, and therefore the temperature in the aquariums was quite constant around $22-23^{\circ} \mathrm{C}$, one day there was a strong storm (the so-called "tramuntana") that induced a drop in temperature of about $5^{\circ} \mathrm{C}$ that persisted for more than $24 \mathrm{~h}$. Two days later, all the animals in the aquariums had spawned. After this observation, using new animals, I was able to repeat the experiment, this time in a controlled way (I kept the animals at $23^{\circ} \mathrm{C}$ for a week and I changed the temperature of the tanks to $18^{\circ} \mathrm{C}$ in the afternoon of day -1 ), and again all the animals spawned during the night of day 0 showing that a long thermal stress $(24 \mathrm{~h})$ was able to induce spawning during the night of the second day. ${ }^{[16]}$ Actually, spawning occurs naturally, without any other kind of induction than the temperature change, unlike what happens with the electric shock in the Florida species. In fact, it has been described that $B$. floridae spawning only takes place when the second meiotic division has occurred. So unfertilized eggs are arrested in metaphase of the second meiotic division. ${ }^{[17]}$ In $B$. lanceolatum it seems that what the temperature change induces is the second meiotic division of the oocytes, a division that is necessary and sufficient for the animals to spawn naturally at sunset. This method has been improved since then and today we do not use a drop in temperature but an increase (from 17 to $23^{\circ} \mathrm{C}$ ) because this allows us to keep adult animals at a lower temperature, which avoids contamination with pathogenic bacteria. On a more personal level, the discovery of this spawning induction method had a major impact, since it made me decide to move and to establish my own research team in the Banyuls sur Mer marine station in 2005.

\section{From Comparative Anatomy to Functional Genomics}

Ernst Haeckel proclaimed: "We begin with the lancelet-after man the most important and interesting of all animals. Man is at the highest summit, the lancelet at the lowest root, of the vertebrate stem." [18] Haeckel probably exaggerated with his assumption, which, moreover, is wrong in evolutionary terms, but despite the fact that amphioxus is not a model species used in many laboratories (probably due to the difficulty in getting access to embryos), since the beginning of the 20th century about 2000 articles have been published on amphioxus (according to the Web of Science in May 2018, searched for: TOPIC: (amphioxus) OR TOPIC: (lancelet) OR TOPIC: (cephalochordate); Timespan: All years (starting in 1900).
Indexes: SCI-EXPANDED, SSCI, A\&HCI, CPCI-S, CPCI-SSH, BKCI-S, BKCI-SSH, ESCI, CCR-EXPANDED, IC. (see Figure 4). As it can be observed in Figure 4, I have divided the history of research using the amphioxus model into three main, partly overlapping, periods.

\subsection{First Period: Comparative Anatomy}

The first period, quite long and with a low but constant number of publications per year, corresponds to the period during which numerous researchers described the anatomy of a number of metazoans (including amphioxus), and used these descriptions to establish evolutionary relationships between the different groups using comparative anatomy. Figure 4 shows only the number of publications from 1900 onwards, but this first period began earlier, in the middle of the 19th century. Some of the most important researchers and works of this period, before the 20th century, described the adult anatomy, but soon the embryology of amphioxus was also characterized. I will cite here some of the most important publications of this period that although not exhaustive, illustrate the type of research that was carried out at that time. As examples of description of adult anatomy and histology we can cite Alexander Kowalevsky, who noted that amphioxus shares key anatomical features with vertebrates, such as a hollow dorsal nerve tube, an endostyle, a segmented body derived from somites and a postanal tail. ${ }^{[19]} \mathrm{De}$ Quatrefages, who described the nervous system of amphioxus, ${ }^{[20]}$ E. Ray Lankester who also described the general morphology of adult amphioxus, ${ }^{[21]}$ and some other early researchers on amphioxus include Heinrich Rathke ${ }^{[22]}$ or John Goodsir. ${ }^{[23]}$ Concerning amphioxus embryology, even though some descriptions of larvae collected from plankton were made by Schultze and Leuckart, ${ }^{[24,25]}$ the first complete description of amphioxus embryos was done by Kowalevsky. ${ }^{[19]}$ Other important contributions to amphioxus embryology include the work of Hatschek or Conklin ${ }^{[26,27]}$ or many years later the experimental embryology work of Tung (reviewed by S. Yan in $1999^{[28]}$ ).

\subsection{Second Period: The Amphioxus Become an EvoDevo Model}

The second period starts when Nicholas and Linda Holland described a method of obtaining amphioxus embryos by induction of spawning in captivity and in vitro fertilization in 1989. ${ }^{8]}$ This second period is characterized by a first subperiod during which using whole-mount in situ hybridization (ISH) on embryos, the study of gene expression was used to establish body plan homologies between amphioxus and vertebrates, ${ }^{[29]}$ and a second subperiod, during which the role of different cellular signals in the control of embryonic development were studied using pharmacological treatments capable of activating or inhibiting these signals (reviewed in Bertrand et al. ${ }^{[30]}$ ). This second period extends until today, as many studies continue to use comparative gene expression and pharmacological treatments to establish homologous relationships of organs or even cell types between amphioxus and vertebrates and to study the 


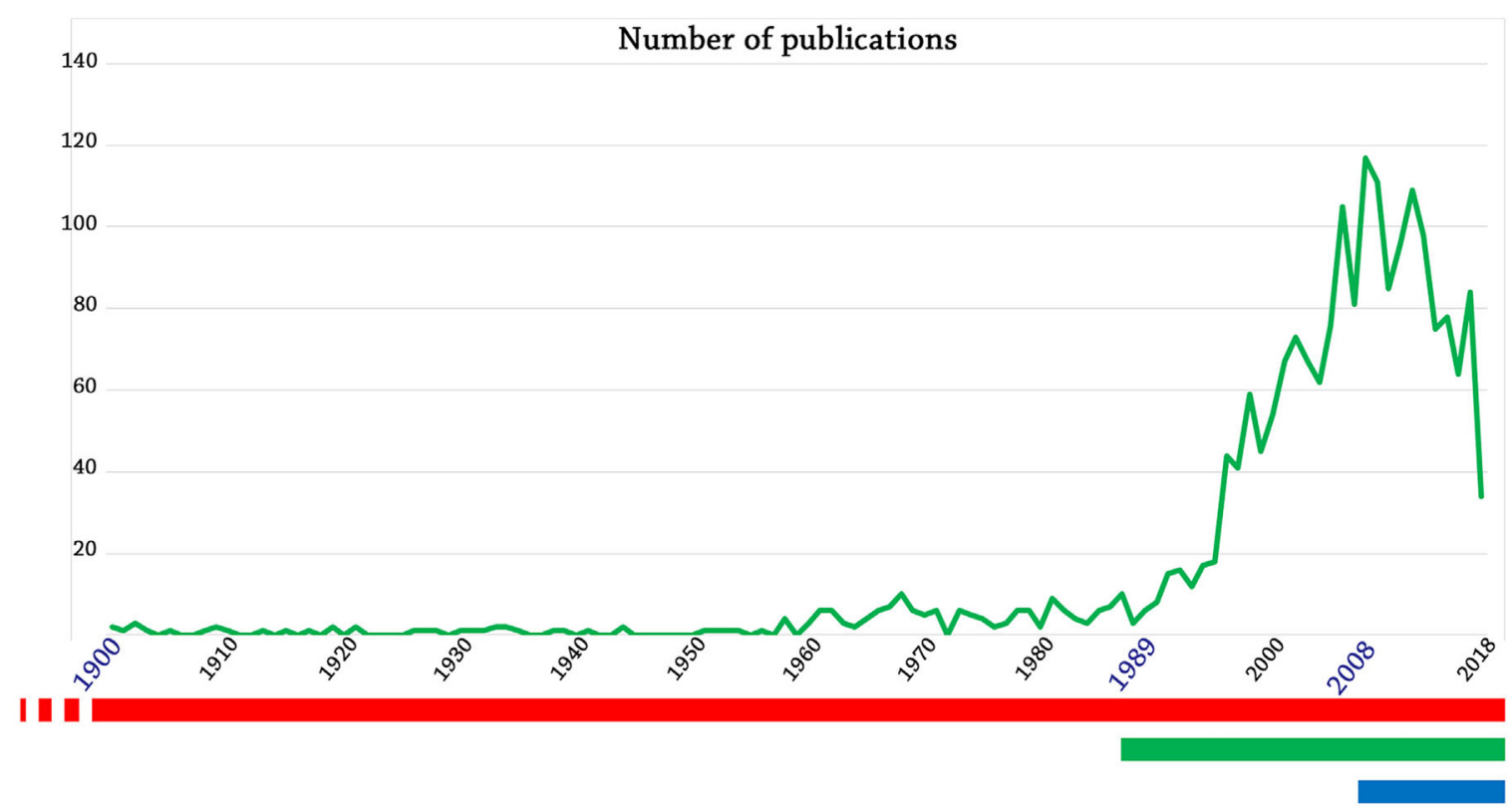

Figure 4. Graphic representation of the number of publications focusing on amphioxus since 1900. The two key dates (1989 and 2008 ) in the evolution of the studies using this animal model are indicated. The red line indicates the period of studies based on anatomical descriptions and comparative anatomy. The green line indicates the period of time that began after developing a method of spawning induction. Research during this period was based first on comparative studies of gene expression, (using the technique of whole-mount in situ hybridization), and later on functional studies using pharmacological treatments. The blue line indicates the period starting after the publication of the first complete genome sequence of an amphioxus (B. floridae), and includes both comparative genomic studies and functional studies using new techniques allowing the specific analysis of the function of a given gene (morpholinos, knock out animal lines using TALEN), or high throughput techniques for the study of chromatin structure.

role of different signals during amphioxus development, respectively.

Obviously there is a considerable amount of publications corresponding to the first subperiod, but here I would like to highlight just a few of them. The first work of this subperiod in which the technique of whole-mount ISH was used to get insights into the relationship between the amphioxus and vertebrate body plans focused on the expression of a gene from the Hox family (Hox3), which is a classic in the world of EvoDevo. ${ }^{[31]}$ This work allowed to establish the existence of a conservation in the anteroposterior patterning of the central nervous system in chordates and suggested the presence of a hindbrain in amphioxus. The study of gene expression of many other genes followed this first work. Different publications suggested conservation of CNS patterning. ${ }^{[32,33]}$ Other genes that have been used to establish homology relationships between amphioxus and vertebrates' structures include Hand, Csx (NkX2.5), and $T b x 4 / 5$, which expression suggests the presence in amphioxus of an homologue of the heart. ${ }^{[34]} \mathrm{A}$ putative homologue of the vertebrate adenohypophysis was also established through the conserved expression of the nuclear receptor $N R 4 A^{[35]}$ together with the expression of the amphioxus orthologs of Pit-1, Eya, Islet, Lhx, Pitx, Six1/2, and Six $3 / 6^{[36-39]}$ The homology between the vertebrate eyes and the frontal eye in amphioxus was proposed given the conserved expression of $\operatorname{Pax} 4 / 6^{[40]}$ as well as the expression of other genes such as Rx, Otx, Pax4/6, Mitf. ${ }^{[41]}$ Also, homology between the endostyle and the thyroid gland was established through the conserved expression of different transcription factor and enzyme genes. ${ }^{[42-45]}$ The conservation of gene expression has also been used as an evidence of homology at the cellular level, such as the expression of Pax3/7 in some amphioxus cells putatively homologous of the vertebrate satellite cells. ${ }^{[46]}$ In this case, instead of ISH, immunolocalization was used to study expression.

As far as the second subperiod is concerned, I will not go into details because most if not all published papers in which a cellcell communication signal has been functionally studied using pharmacological treatments have recently been reviewed by Bertrand et al. ${ }^{[30]}$ However, I would like to say that the use of different drugs has been, and still is, an extremely powerful tool to perform functional studies in amphioxus, due to the experimental simplicity and the large number of embryos that can be obtained in one spawning night (a medium size female may spawn 2-3 thousand eggs), which allows one to perform numerous treatments at different drug concentrations in a fast, simple and reproducible way.

\subsection{Third Period: Functional Genomics}

Finally, the third period starts in 2008, when the first complete sequence of an amphioxus genome (Branchiostoma floridae) is published. ${ }^{[4]}$ This period also extends until today and it includes on the one hand numerous studies in genomics and comparative genomics, and, on the other hand, as a result of the development of new techniques, different functional studies establishing the role of several cellular signals throughout embryonic development. 
The first complete sequence of an amphioxus genome was published for the American species (B. floridae) in $2008^{[47]}$ and was followed a few years later by the publication of the genome of the Asian species (B. belcheri) ${ }^{[48]}$ and, recently, of the Mediterranean species (B. lanceolatum). ${ }^{[49]}$

Susumu Ohno hypothesized in 1970 the existence of a double duplication of the vertebrate genome. ${ }^{[50]}$ Since then, this question has been one of the most discussed issues in the field of evolutionary genomics. In 1994, Jordi Garcia-Fernandez and Peter Holland carried out a work that was the starting point for numerous subsequent studies. ${ }^{[51]}$ In this work, they demonstrated the presence of a single cluster of Hox genes in the amphioxus genome, suggesting that the double duplication of the genome must have occurred after the evolutionary divergence of cephalochordates. Although the demonstration of the existence of this double duplication of the genome (the socalled 2R) in the ancestor of vertebrates (and therefore after the divergence of cephalochordates and urochordates) (Figure 1) was carried out in $2005,{ }^{[52]}$ the complete sequence of the amphioxus genome corroborated this study, closed the discussion about the timing of the $2 \mathrm{R}$ and allowed the reconstruction of the ancestral karyotype of chordates. ${ }^{[4]}$

Access to the complete genome sequence of amphioxus allowed the realization of a great number of studies on the evolutionary history of different gene families such as the homeobox, ${ }^{[53,54]}$ the tyrosine kinase receptor, ${ }^{[55]}$ the nuclear receptor ${ }^{[53,56]}$ or the opsin gene families. ${ }^{[53,57]}$ Other studies have focused more on the presence/absence of genes involved in a given function, such as, for example, genes known to be involved in immunity ${ }^{[58]}$ or in the neural crest gene regulatory network. ${ }^{[59]}$ Apart from the specific interest of these studies in the context of the evolution of the different gene families, we can extract an important trait of the amphioxus genome, which is its high conservation in terms of gene content. In fact, it seems that amphioxus has retained a gene content very close to the gene content that was probably present in the ancestor of all chordates. ${ }^{[60]}$ This characteristic is unique within chordates since both urochordates and vertebrates lost numerous genes during their evolutionary histories. However, this trait does not mean that the amphioxus genome is equivalent to the genome of the chordate ancestor (in terms of gene content) since numerous lineage-specific gene duplications occurred in cephalochordates.

In this last period of publications, I would like to highlight a separate group of studies, which represents only a few articles. However, these publications use new techniques with a huge potential for functional studies in amphioxus and I consider they are the first of a "new era" in amphioxus research. Some of these works concern the development of aquaculture techniques, which allowed the development of new approaches. For example, to study regeneration in adult amphioxus, a process that takes between 3 to 4 months in $B$. lanceolatum, it was necessary to develop an aquaculture system allowing keeping adult individuals separately for such a long period in small water volumes. ${ }^{[61]}$ Other techniques that have represented great advances are the induction of spawning by temperature change that I already mentioned above, ${ }^{[16]}$ which allows one to obtain embryos on a daily basis during the spawning season, or the development of husbandry techniques with artificial sea water, ${ }^{[62]}$ which allows laboratories inland to work with amphioxus. Obtaining the complete life cycle of amphioxus in captivity ${ }^{[63-66]}$ has also been a very important step, particularly to create knockout lines of amphioxus using transcription activator-like effector nucleases, (TALEN)-based knockout. ${ }^{[67]}$ This knockout technique allowed Li and collaborators to demonstrate the master role of the Nodal antagonist Cerberus in the control of left-right asymmetries in amphioxus. ${ }^{[67]}$ Other techniques allowing functional studies developed by various laboratories include the use of morpholinos to knockdown gene expression or the overexpression of a given gene through microinjection of capped-mRNA. These studies include the overexpression of chimeric transcription factors acting as constitutive repressors as a result of the fusion of the Drosophila Engrailed repressor domain to the sequence of a given transcription factor. ${ }^{[67]}$ The first morpholino microinjected in amphioxus embryos was a morpholino blocking the expression of Hox1. This study showed a posteriorized phenotype in knockdown embryos and demonstrated that Hox 1 mediates the role of RA signaling in setting the posterior limit of the pharynx. ${ }^{[68]}$ Other studies using morpholino approaches include knockdown of Chordin and Blimp, ${ }^{[69]}$ Dkk3, ${ }^{[70]}$ and Tbx1/10. ${ }^{[71]}$ The first of these studies showed that Nodal/Vg1 and Bmp signaling act in opposition for the specification and maintenance of the dorso-ventral and antero-posterior axes. ${ }^{[69]}$ The second one focused on the role of $D k k 3$, a secreted protein of the Dickkopf family, in the control of development of anterior structures in amphioxus, showing that the knockdown of $D k k 3$ produces a headless phenotype similar to the phenotype produced by upregulation of Wnt $\beta$ catenin signalling. ${ }^{[70]}$ Then, the third study showed how a regulatory network involving the mutual inhibition of retinoic acid (RA) and Tbx1/10 signaling is involved in the control of pharyngeal segmentation. ${ }^{[71]}$ Lastly, microinjection of reporter constructs to test the enhancer/promoter activity of cisregulatory DNA and particularly cross-species regulatory comparisons on key developmental genes is an extremely powerful approach to gain insight into the cis-regulatory mechanisms underlying developmental evolution. The first study using this approach, by Yu et al., ${ }^{[72]}$ showed the reliability of the technique and was followed by many other studies that have been reviewed in Kozmikova et al. ${ }^{[3]}$ Since 2015 other studies have used this technique to describe the regulatory activities of SoxE ${ }^{[74]}$ and $\mathrm{Gsx}^{[75]}$ upstream regulatory elements and their evolutionary implications, or more recently to show the putative enhancer activity of non-coding sequences in the vicinity of the amphioxus hox cluster. ${ }^{[49]}$

Finally, the development of high throughput techniques such as chromosome conformation capture followed by high throughput sequencing (4C-seq) or Assay for TransposaseAccessible Chromatin with high throughput sequencing (ATACseq), have recently allowed to study the amphioxus chromatin conformation and the presence of presumptive active enhancers in the genome. ${ }^{[49]}$ This study has shown important differences in the 3D structure of the chromatin around the Hox cluster between amphioxus and vertebrates. It is well known that the 3D structure of this locus in vertebrates is very important for its function in the patterning of the limbs. ${ }^{[76]}$ The loci of the HoxA and HoxD complexes of vertebrates are organized in a threedimensional bipartite structure (in two so-called topologically associated domains, TADs). These TADs contain distant 
regulatory elements on both sides of the Hox complex that are essential for the regulation of Hox genes expression in the limbs. However, in amphioxus its unique Hox cluster is structured into a single TAD that contains only a few regulatory elements. Thus, this study suggests that the evolution of the three-dimensional structure of chromatin must have played a central role in the appearance and evolution of vertebrate limbs.

\section{The Future of Research Using the Amphioxus Model}

The techniques that I have just presented here, and in particular those that allow us to understand the specific function of different genes in developmental processes (such as knockdown and knockout techniques), or how gene expression is regulated (such as the 4C-seq and ATAC-seq techniques), will allow remarkable progress to be made in the coming years. Without any doubt, the use of these techniques will allow notable advances in the understanding of the mechanisms that regulate the embryonic development of amphioxus. But despite the enormous technical advances that have taken place in the research world of the amphioxus model, we always have to keep in mind one thing: that there is always a model in biology to answer a specific question. The amphioxus model has been, is, and probably will be, the best existing model to understand the evolutionary changes that occurred during chordate evolution and that allowed the appearance of the vertebrates, including humans.

\section{Acknowledgements}

The author thanks Stephanie Bertrand for proofreading and her continuous collaboration in our common laboratory. The author also thanks the CNRS and the ANR (ANR16-CE12-0008-01 to HE) for funding our research projects.

\section{Conflict of Interest}

The author declares no conflict of interest.

\section{Keywords}

amphioxus, cephalochordates, Evo-Devo, invertebrate chordate, lancelet, vertebrates

[1] O. G. Costa, Annuario Zoologico, Tipografia di Azzolino e Comp, Napoli 1834, p. 49.

[2] M. Schubert, H. Escriva, J. Xavier-Neto, V. Laudet, Trends. Ecol. Evol. 2006, 21, 269.

[3] S. J. Bourlat, T. Juliusdottir, C. J. Lowe, R. Freeman, J. Aronowicz, M. Kirschner, E. S. Lander, M. Thorndyke, H. Nakano, A. B. Kohn, A. Heyland, L. L. Moroz, R. R. Copley, M. J. Telford, Nature 2006, 444, 85.
[4] F. Delsuc, H. Brinkmann, D. Chourrout, H. Philippe, Nature 2006 439, 965.

[5] F. Delsuc, G. Tsagkogeorga, N. Lartillot, H. Philippe, Genesis 2008, 46, 592.

[6] R. C. Brusca, G. J. Brusca, Invertebrates, Sinauer Associates, Sunderland 1990.

[7] H. Escriva, R. Safi, C. Hanni, M. C. Langlois, P. Saumitou-Laprade, D. Stehelin, A. Capron, R. Pierce, V. Laudet, Proc. Natl. Acad. Sci. U. S. A. 1997, 94, 6803.

[8] N. D. Holland, L. Z. Holland, Biol. Bull. 1989, 176, 111.

[9] S. G. Poss, H. T. Boschung, Israel. J. Zool. 1996, 42, 13.

[10] T. Nishikawa, Zoolog. Sci. 2004, 21, 1131.

[11] T. Kon, M. Nohara, Y. Yamanoue, Y. Fujiwara, M. Nishida, T. Nishikawa, BMC Evol. Biol. 2007, 7, 127.

[12] M. D. Stokes, N. D. Holland, Invertebrate Biol. 1996, 115, 349.

[13] M. Fuentes, E. Benito, S. Bertrand, M. Paris, A. Mignardot, L. Godoy, S. Jimenez-Delgado, D. Oliveri, S. Candiani, E. Hirsinger, S. D'Aniello, J. Pascual-Anaya, I. Maeso, M. Pestarino, P. Vernier, J. F. Nicolas, M. Schubert, V. Laudet, A. M. Geneviere, R. Albalat, J. Garcia Fernandez, N. D. Holland, H. Escriva, J. Exp. Zoolog. B Mol. Dev. Evol. 2007, 308, 484.

[14] F. Monniot, Vie et Milieu. 1962, XIII, 232.

[15] X. H. Wu, S. C. Zhang, Y. Y. Wang, B. L. Zhang, Y. M. Qu, X. J. Jiang, Chin. J. Oceanol. Limnol. 1994, 12, 289.

[16] M. Fuentes, M. Schubert, D. Dalfo, S. Candiani, E. Benito, J. Gardenyes, L. Godoy, F. Moret, M. Illas, I. Patten, J. Permanyer, D. Oliveri, G. Boeuf, J. Falcon, M. Pestarino, J. G. Fernandez, R. Albalat, V. Laudet, P. Vernier, H. Escriva, J. Exp. Zoolog. Part B Mol. Dev. Evol. 2004, 302, 384.

[17] L. Z. Holland, N. D. Holland, Biol. Bull. 1992, 182, 77.

[18] E. Haeckel, The Evolution of Man; a Popular Scientific Study, Watts \& Co., London 1905.

[19] A. O. Kowalevsky, Mém. Acad. Sci. St. Petersb. 1867, 11, 1.

[20] M. A. de Quatrefages, Annales des sciences naturelles, Vol. IV, (Ed: M. E. C. Fortin), Libraires-editeurs, Paris 1845, p. 197.

[21] E. R. Lankester, Q. J. Microsc. Sci. 1889, 29, 365.

[22] H. Rathke, Bemerkungen uber den Bau des Amphioxus lanceolatus eines Fisches aus der Ordnung der Cyclostomen, Gebrüder Bornträger, Königsberg 1841.

[23] J. Goodsir, Proc. R. Soc. Edinb. 1844, 15, 247.

[24] M. Schultze, Z. Wiss. Zool. 1851, 416.

[25] R. Leuckart, A. Pagenstecher, Arch. Anat. Physiol. Wiss. Med. 1858, $1851,558$.

[26] B. Hatschek, The Amphioxus and Its Development, Macmillan \& CO, New York 1893

[27] E. G. Conklin, J. Morph. 1932, 54, 69.

[28] S. Yan, Dev. Growth. Differ. 1999, 41, 503.

[29] L. Z. Holland, P. W. H. Holland, N. D. Holland, Molecular Zoology: Advances, Strategies, and Protocols (Eds: J. D. Ferraris, S. R. Palumbi), Wiley-Liss, New York 1996, p. 267.

[30] S. Bertrand, Y. Le Petillon, I. M. L. Somorjai, H. Escriva, Int. J. Dev. Biol. 2017, 61, 697.

[31] P. W. Holland, L. Z. Holland, N. A. Williams, N. D. Holland, Development 1992, 116, 653.

[32] L. Z. Holland, J. E. Carvalho, H. Escriva, V. Laudet, M. Schubert, S. M. Shimeld, J. K. Yu, Evodevo 2014, 4, 27.

[33] B. Albuixech-Crespo, L. Lopez-Blanch, D. Burguera, I. Maeso, L. Sanchez-Arrones, J. A. Moreno-Bravo, I. Somorjai, J. PascualAnaya, E. Puelles, P. Bovolenta, J. Garcia-Fernandez, L. Puelles, M. Irimia, J. L. Ferran, PLoS Biol. 2017, 15, e2001573.

[34] J. Pascual-Anaya, B. Albuixech-Crespo, I. M. Somorjai, R. Carmona Y. Oisi, S. Alvarez, S. Kuratani, R. Munoz-Chapuli, J. Garcia-Fernandez, Dev. Biol. 2012, 375, 182.

[35] S. Candiani, L. Moronti, M. Pestarino, Ann. N. Y. Acad. Sci. 2009, $1163,361$. 
[36] W. R. Jackman, J. A. Langeland, C. B. Kimmel, Dev. Biol. 2000, 220, 16.

[37] Y. Wang, P. Zhang, K. Yasui, H. Saiga, Mech. Dev. 2002, 117, 315.

[38] Z. Kozmik, N. D. Holland, J. Kreslova, D. Oliveri, M. Schubert, K. Jonasova, L. Z. Holland, M. Pestarino, V. Benes, S. Candiani, Dev. Biol. 2007, 306, 143.

[39] S. Candiani, N. D. Holland, D. Oliveri, M. Parodi, M. Pestarino, Brain Res. Bull. 2008, 75, 324.

[40] S. Glardon, L. Z. Holland, W. J. Gehring, N. D. Holland, Development 1998, 125, 2701.

[41] P. Vopalensky, J. Pergner, M. Liegertova, E. Benito-Gutierrez, D. Arendt, Z. Kozmik, Proc. Natl. Acad. Sci. U. S. A. 2012, 109, 15383.

[42] T. V. Venkatesh, N. D. Holland, L. Z. Holland, M. T. Su, R. Bodmer, Dev. Genes Evol. 1999, 209, 254.

[43] M. Ogasawara, Dev. Genes Evol. 2000, 210, 231.

[44] J. Hiruta, F. Mazet, K. Yasui, P. Zhang, M. Ogasawara, Dev. Dyn. 2005, 233, 1031.

[45] F. Mazet, G. N. Luke, S. M. Shimeld, Gene Expr. Patterns 2005, 5, 313.

[46] I. M. Somorjai, R. L. Somorjai, J. Garcia-Fernandez, H. Escriva, Proc. Natl. Acad. Sci. U. S. A. 2012, 109, 517.

[47] N. H. Putnam, T. Butts, D. E. Ferrier, R. F. Furlong, U. Hellsten, T. Kawashima, M. Robinson-Rechavi, E. Shoguchi, A. Terry, J. K. Yu, E. L. Benito-Gutierrez, I. Dubchak, J. Garcia-Fernandez, J. J. GibsonBrown, I. V. Grigoriev, A. C. Horton, P. J. de Jong, J. Jurka, V. V. Kapitonov, Y. Kohara, Y. Kuroki, E. Lindquist, S. Lucas, K. Osoegawa, L. A. Pennacchio, A. A. Salamov, Y. Satou, T. SaukaSpengler, J. Schmutz, I. T. Shin, A. Toyoda, M. Bronner-Fraser, A. Fujiyama, L. Z. Holland, P. W. Holland, N. Satoh, D. S. Rokhsar, Nature 2008, 453, 1064.

[48] S. Huang, Z. Chen, X. Yan, T. Yu, G. Huang, Q. Yan, P. A. Pontarotti, H. Zhao, J. Li, P. Yang, R. Wang, R. Li, X. Tao, T. Deng, Y. Wang, G. Li, Q. Zhang, S. Zhou, L. You, S. Yuan, Y. Fu, F. Wu, M. Dong, S. Chen, A. Xu, Nat. Comm. 2014, 5, 5896.

[49] R. D. Acemel, J. J. Tena, I. Irastorza-Azcarate, F. Marletaz, C. GomezMarin, E. de la Calle-Mustienes, S. Bertrand, S. G. Diaz, D. Aldea, J. M. Aury, S. Mangenot, P. W. Holland, D. P. Devos, I. Maeso, H. Escriva, J. L. Gomez-Skarmeta, Nat. Genet. 2016, 48, 336.

[50] S. Ohno, Evolution by Gene Duplication, Springer-Verlag, Heidelberg 1970.

[51] J. Garcia-Fernandez, P. W. H. Holland, Nature 1994, 370, 563.

[52] P. Dehal, J. L. Boore, PLoS Biol. 2005, 3, 314.

[53] L. Z. Holland, R. Albalat, K. Azumi, E. Benito-Gutierrez, M. J. Blow, M. Bronner-Fraser, F. Brunet, T. Butts, S. Candiani, L. J. Dishaw, D. E. Ferrier, J. Garcia-Fernandez, J. J. Gibson-Brown, C. Gissi, A. Godzik, F. Hallbook, D. Hirose, K. Hosomichi, T. Ikuta, H. Inoko, M. Kasahara, J. Kasamatsu, T. Kawashima, A. Kimura, M. Kobayashi, Z. Kozmik, K. Kubokawa, V. Laudet, G. W. Litman, A. C. McHardy, D. Meulemans, M. Nonaka, R. P. Olinski, Z. Pancer, L. A. Pennacchio, M. Pestarino, J. P. Rast, I. Rigoutsos, M. Robinson-Rechavi, G. Roch,
H. Saiga, Y. Sasakura, M. Satake, Y. Satou, M. Schubert, N. Sherwood, T. Shiina, N. Takatori, J. Tello, P. Vopalensky, S. Wada, A. Xu, Y. Ye, K. Yoshida, F. Yoshizaki, J. K. Yu, Q. Zhang, C. M. Zmasek, P. J. de Jong, K. Osoegawa, N. H. Putnam, D. S. Rokhsar, N. Satoh, P. W. Holland, Genome Res. 2008, 18, 1100.

[54] N. Takatori, T. Butts, S. Candiani, M. Pestarino, D. E. Ferrier, H. Saiga, P. W. Holland, Dev. Genes Evol. 2008, 218, 579.

[55] S. D'Aniello, M. Irimia, I. Maeso, J. Pascual-Anaya, S. JimenezDelgado, S. Bertrand, J. Garcia-Fernandez, Mol. Biol. Evol. 2008, 25, 1841.

[56] M. Schubert, F. Brunet, M. Paris, S. Bertrand, G. Benoit, V. Laudet, Dev. Genes Evol. 2008, 218, 651.

[57] C. N. Pantzartzi, J. Pergner, I. Kozmikova, Z. Kozmik, Int. J. Dev. Biol. 2017, 61, 763.

[58] S. Huang, S. Yuan, L. Guo, Y. Yu, J. Li, T. Wu, T. Liu, M. Yang, K. Wu, H. Liu, J. Ge, Y. Yu, H. Huang, M. Dong, C. Yu, S. Chen, A. Xu, Genome Res. 2008, 18, 1112.

[59] J. K. Yu, D. Meulemans, S. J. McKeown, M. Bronner-Fraser, Genome Res. 2008, 18, 1127.

[60] A. Louis, H. Roest Crollius, M. Robinson-Rechavi, Brief. Funct. Genomics 2012, 11, 89.

[61] I. M. L. Somorjai, A. Camasses, B. Rivière, H. Escrivà, Aquaculture 2008, 281, 145.

[62] M. Theodosiou, A. Colin, J. Schulz, V. Laudet, N. Peyrieras, J. F. Nicolas, M. Schubert, E. Hirsinger, J. Exp. Zool. B Mol. Dev. Evol. 2011, 316, 263.

[63] K. Yasui, M. Urata, N. Yamaguchi, H. Ueda, Y. Henmi, Zoolog. Sci. 2007, 24, 514

[64] Q. J. Zhang, Y. Sun, J. Zhong, G. Li, X. M. Lu, Y. Q. Wang, J. Exp. Zoolog. B Mol. Dev. Evol. 2007, 308, 464.

[65] G. Li, X. Yang, Z. Shu, X. Chen, Y. Wang, PLoS ONE 2012, 7, e50838.

[66] G. Li, Z. Shu, Y. Wang, PLoS ONE 2013, 8, e75461.

[67] G. Li, X. Liu, C. Xing, H. Zhang, S. M. Shimeld, Y. Wang, Proc. Natl. Acad. Sci. U. S. A. 2017, 114, 3684.

[68] M. Schubert, J. K. Yu, N. D. Holland, H. Escriva, V. Laudet, L. Z. Holland, Development 2005, 1, 61.

[69] T. Onai, J. K. Yu, I. L. Blitz, K. W. Cho, L. Z. Holland, Dev. Biol. 2010, $344,377$.

[70] T. Onai, A. Takai, D. H. Setiamarga, L. Z. Holland, Evol. Dev. 2012, 14, 338.

[71] D. Koop, J. Chen, M. Theodosiou, J. E. Carvalho, S. Alvarez, A. R. de Lera, L. Z. Holland, M. Schubert, Evodevo 2014, 5, 36.

[72] J. K. Yu, N. D. Holland, L. Z. Holland, Dev. Biol. 2004, 274, 452.

[73] I. Kozmikova, Z. Kozmik, Mar. Genomics 2015, 24, 159.

[74] D. Jandzik, A. T. Garnett, T. A. Square, M. V. Cattell, J. K. Yu, D. M. Medeiros, Nature 2015, 518, 534.

[75] M. G. Garstang, P. W. Osborne, D. E. Ferrier, BMC Evol. Biol. 2016, 16, 57.

[76] G. Andrey, T. Montavon, B. Mascrez, F. Gonzalez, D. Noordermeer, M. Leleu, D. Trono, F. Spitz, D. Duboule, Science 2013, 340, 1234167. 